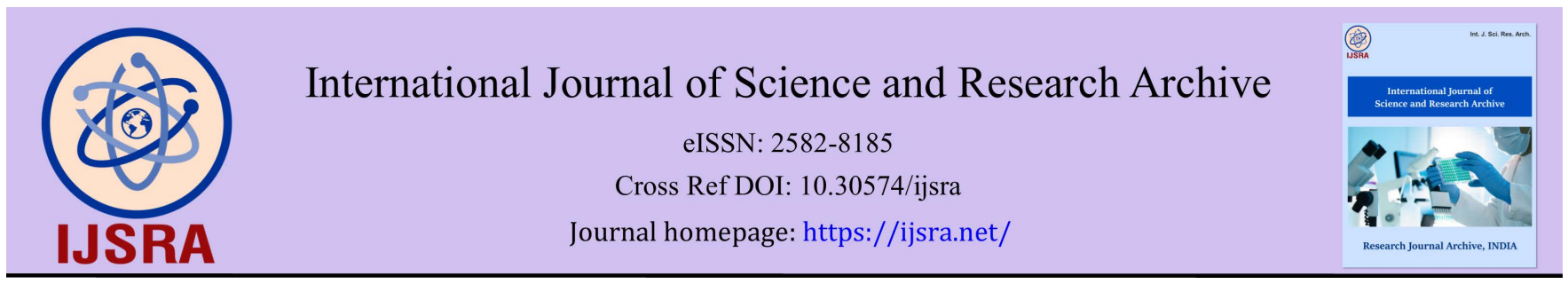

(RESEARCH ARTICLE)

\title{
Larvicidal effect of some natural products on mosquito and some aquatic predators in Gezira State, Sudan: Field assessment
}

\author{
Abdelmonem Eltiyab Houmida Ali ${ }^{1}$ and Mutaman Ali A. Kehail 2,* \\ ${ }^{1}$ King Khalid University (KKU), Muhayel Asser, KSA. \\ ${ }^{2}$ Faculty of Science, University of Gezira, Sudan.
}

International Journal of Science and Research Archive, 2021, 03(02), 078-082

Publication history: Received on 13 August 2021; revised on 21 September 2021; accepted on 23 September 2021

Article DOI: https://doi.org/10.30574/ijsra.2021.3.2.0134

\begin{abstract}
There are many methods used for mosquito control. Depending on the situation, source reduction (removing stagnant water), bio-control (importing natural predators), trapping, and insecticides to kill larvae or adults may be used. Some aquatic predators were reputed as biological control agents for mosquito larvae. Hence they have to be considered when experimenting on the lethal effects of any material on mosquito larvae. The objectives of this study were to study the effects of neem leaves and usher latex against Anopheles and Culex larvae and some of their aquatic predators (hemipteran boatman (HB), tadpole (T), swimming beetle larvae (SBL) and adult (SBA) and mayfly naiad (MF)) in some breeding sites around Wad Medani Town. Gezira State, Sudan. Two villages were selected for conducting this study. The count of the mosquito larvae and the aquatic predators continued for four days from applying natural products. The results showed that, mosquito's larvae were affected more than the aquatic by Neem leaves and Ushar latex. The study of the microclimates in the breeding sites will help to correlate toxicity to any level of any environmental factor.
\end{abstract}

Keywords: Neem; Ushar; Neem; Mosquito; Aquatic predators; Gezira State- Sudan

\section{Introduction}

Mosquitoes are small insects belong to the family Culicidae; order Diptera. Mosquitoes have one pair of wings, three pairs of long hair-like legs, slender segmented body, feathery antennae, and elongated mouthparts (called a proboscis) that can pierce the skin of a host and feed on blood. Mosquitoes go through four stages in their life cycle: egg, larva, pupa, and adult or imago [1]. The first three stages are aquatic and last for 5-14 days, depending on the species and the ambient temperature. Adults live for 4-8 weeks. Mosquito species feeds on the blood of various hosts, including most vertebrates and some invertebrates, primarily other arthropods [2, 3].

The mosquito's saliva which transferred to the host during the bite, can cause an itchy rash, and transmit some pathogens (such as malaria parasites [4], yellow fever, Chikungunya, West Nile, dengue fever, filariasis, Zika and other arboviruses. By transmitting diseases, mosquitoes can cause the deaths to human and some vertebrates more than any other animal taxon [5].

In order to predict mosquito-borne disease spread in relation to climate, two types of models are used: correlative models and mechanistic models.These models have been used to predict the potential risk of a vector-borne disease based on an areas forecasted climate [6].

Insecticides resistance in Anopheles arabiensis population from Gezira, Sudan has produced strains showing very low mortality when exposed to malathion (the same dose and exposure time resulted in $100 \%$ mortality in other

*Corresponding author: Mutaman Ali A. Kehail

Faculty of Science, University of Gezira, Sudan.

Copyright $(2021$ Author(s) retain the copyright of this article. This article is published under the terms of the Creative Commons Attribution Liscense 4.0. 
populations of the species of A. gambiae). Resistance to fenthion detected in Culex quinquefasciatus was also reported [7]. One of the general measures to counteract resistance and environmental pollution caused by insecticides is by using natural products, which are, cheap, available, easily applied and relatively safe.

Neem (Azadirachta indica) is a tree in the mahogany family Meliaceae. and is native to India Subcontinent, growing in tropical and sub-tropical regions in alluding Sudan [8]. Neem oil can cause some forms of toxicity if consumed in large quantities [9]. Imaranet al. [10] studied the neem leaves phytochemistry.

Ushar (Calotropis procera) is a species of flowering plant in the dogbane family, Apocynaceae, which is native to North Africa, tropical Africa, Western Asia, South Asia, and Indochina. It grows all over the Sudan. Both Neem and Usher preparation were reacted to give promising relit in insect pest control in finding [11]. The milky exudation from the plant is toxic. Calotropin, a compound in the latex, is more toxic compound. The latex is also harmful to the eyes [12].

This study aims to evaluate the effects ofneem ( $A$. indica) leaves and usher ( $C$. procera) latex against mosquito's (Anopheles and Culex) larvae and some of their aquatic predators in some breeding sites around Wad Medani City (Karkoug and Barakat villages), Gezira State, Sudan.

\section{Material and methods}

\subsection{Study area}

The breeding sites of Barakat and Karkoug villages were selected for testing the potentiality of the some natural products and sampling mosquitoes (Anopheles and Culex) larvae and aquatic predators. These villages were more or less located to the west (Karkoug) and south (Barakat) of Wad Medani City, Gezira State, Sudan.

\subsection{Materials}

The leaves of neem ( $A$. indica) and the latex of Ushar ( $C$. procera) plant used as basic materials in this study, were collected from the gardens of the University of Gezira, main campus. The Ushar latex was collected from the aerial parts of the plant. The plant stems and leaves were cut by using a sharp small knife and the flowing latex was then sucked by $5 \mathrm{ml}$ syringe and then the samples were transferred into small, cleaned glass containers.

The collected neem leaves were immediately cleaned then dried at room temperature under shade away from the direct sunlight. The dried leaves were crushed to fine particles using a mortar. The plant materials were then ready for the field assessment of their potentialities in the breeding sites of the study area.

\subsection{Field application of plant products}

The volume of breeding water in each selected site was estimated just before the potentiality test was run, then $10 \mathrm{~g}$ of the dried sample of the neem leaves were added to each breeding site per liter water $(10 \mathrm{~g} / \mathrm{L})$.

The raw usher latex was tested as 50\% aqueous latex ( $1 \mathrm{ml}$ latex: $1 \mathrm{ml}$ water). The aqueous Ushar latex was applied at a concentration of $\mathbf{1 0} \mathrm{ml} / \mathrm{L}$ breeding water. The prepared mixtures were tested immediately and never stored for a while.

\subsection{Counting of mosquito larvae and the aquatic predators}

Sampling from breading sites of each village was done daily for successive four days for each breeding site. Larvae of Anopheles (An) and Culex (CL) mosquitoes, great diving beetles (larvae (SBL) and adults (SBA), hemipteran boatman (HB), mayfly naiads (MF) and tadpoles (T) that were collected during sampling were immediately separated, counted and discarded.

\section{Results and discussion}

\subsection{The effect of neem leaves powder}

In Karkoug breeding sites, the reduction of (An) and (CL) reached 100\% after 72 hours (from 854 to 52, 4 and 0 for (An) and from 220 to 19, 3 and 0 for (CL). The aquatic predators also deteriorated against neem leaves (NL) product; (MF) was completely disappeared (from 6 to 3, 3 and 0 after 72 hours), while (SBA) and (HB) were slightly affected (from 4 to 2 after 72 hours), whereas, (SBL) and (T) were not seen in these breeding sites (Table, 1). 
In Barakat breeding sites, the reduction of (An) and (CL) also reached 100\% after 72 hours. The aquatic predators were slightly affected with (NL) product; the (MF), (SBA) and (SBL) lost not more than two individuals, whereas (HB) was not affected, while (T) was not found at that period (Table, 1).

Kehail [13] found that, neem leaves powder resulted in 100\% mortality in Anopheles larvae, while the highest mortality in Culex larvae occurred at the first day, but it did not reach $100 \%$. The potentiality of neem leaves powder against Anopheles and Culex mosquitos' larvae, were reviewed by some researchers e.g., AbdAldafae [14], and 0sman [15]. The important constituents in neem are margostic acid, the alkaloid azadirachtin, margaspierine and margosine [16], which were seemed to be responsible for death in larval populations.

Table 1Count of Anopheles and Culex larvae and some of their aquatic predators in Karkoug and Barakat breeding sites treated with $A$. indica leaves powder at $10 \mathrm{~g} / \mathrm{L}$ breeding water

\begin{tabular}{|c|c|c|c|c|c|c|c|c|}
\hline Site & Day & HB & T & SBL & SBA & MF & CL & An \\
\hline \multirow{5}{*}{ Karkoug } & 1 & 4 & 0 & 0 & 4 & 6 & 220 & 854 \\
\cline { 2 - 9 } & 2 & 3 & 0 & 0 & 3 & 3 & 19 & 52 \\
\cline { 2 - 9 } & 3 & 3 & 0 & 0 & 2 & 3 & 3 & 4 \\
\cline { 2 - 9 } & 4 & 2 & 0 & 0 & 2 & 0 & 0 & 0 \\
\hline \multirow{5}{*}{ Barakat } & 1 & 2 & 0 & 4 & 3 & 8 & 67 & 351 \\
\cline { 2 - 9 } & 2 & 2 & 0 & 3 & 3 & 7 & 4 & 15 \\
\cline { 2 - 9 } & 3 & 2 & 0 & 2 & 3 & 6 & 0 & 1 \\
\cline { 2 - 9 } & 4 & 2 & 0 & 2 & 2 & 6 & 0 & 0 \\
\hline
\end{tabular}

MF= mayfly naiads; $\mathbf{S B A}=$ swimming beetle (adult); $\mathbf{S B L}=$ swimming beetle (larvae); $\mathbf{T}=$ tadpole; $\mathbf{H B}=$ hemipteran boatman

\subsection{The effect of aqueous Ushar latex}

Table (2) showed that, the aqueous usher latex (AUL) mixture as a control material, decreased the density of (An; 600 larvae) and (CL; 400 larvae) to reached $99.5 \%$ and 100\%, respectively, after 72 hours. The aquatic predators were also affected with AUL; $58 \%$ of (MF), $50 \%$ of (SBA) and (SBL), $100 \%$ of (HB), while $43 \%$ of (T) were controlled at that period, considering that, their densities did not exceed 20 individuals, except $(\mathrm{T})$.

Table 2 Count of Anopheles and Culex larvae and some of their aquatic predators in Karkoug breeding site treated with aqueous ushar latex at $10 \mathrm{ml} / \mathrm{L}$ breeding water

\begin{tabular}{|l|c|c|c|c|c|c|c|c|}
\hline Site & Day & HB & T & SBL & SBA & MF & CL & An \\
\hline \multirow{4}{*}{ Karkoug } & 1 & 2 & 30 & 4 & 20 & 12 & 400 & 600 \\
\cline { 2 - 9 } & 2 & 1 & 21 & 3 & 14 & 9 & 54 & 80 \\
\cline { 2 - 9 } & 3 & 1 & 16 & 3 & 12 & 8 & 11 & 12 \\
\cline { 2 - 9 } & 4 & 0 & 13 & 2 & 10 & 7 & 0 & 3 \\
\hline \multirow{5}{*}{ Barakat } & 1 & 3 & 5 & 4 & 6 & 4 & 40 & 100 \\
\cline { 2 - 9 } & 2 & 1 & 4 & 3 & 4 & 3 & 12 & 20 \\
\cline { 2 - 9 } & 3 & 2 & 3 & 2 & 3 & 2 & 4 & 4 \\
\cline { 2 - 9 } & 4 & 1 & 2 & 3 & 2 & 2 & 0 & 1 \\
\hline
\end{tabular}

$\mathrm{MF}=$ mayfly naiads; $\mathrm{SBA}=$ swimming beetle (adult); $\mathrm{SBL}=$ swimming beetle (larvae); $\mathrm{T}=$ tadpole; $\mathrm{HB}=$ hemipteran boatman

At Barakat area, using the AUL mixture, the reduction of (An) and (CL) reached 100\% just after 48 hours (from 100 to 20, 4 and 0 for $(\mathrm{An})$ and from 40 to 12, 4 and 0 for (CL)). The aquatic predators were also affected with AUL mixture; $50 \%$ of (MF), $67 \%$ of (SBA), and (HB) population were controlled, while $25 \%$ of (SBL) and $60 \%$ of (T) were also lost. 
Ushar is rich in different chemical compounds. The active principles of the juice were calctin, calotropin, calotoxin and uschardin which are poisonous in nature [17]. The plant contains a very toxic glycoside [18].

NL produced $100 \%$ control in (An) and (CL) larvae, while not more than $50 \%$ of the aquatic predators submitted to this material were killed. AUL mixture showed relatively similar control percentage (more than $97 \%$ ) against mosquito's larvae, while the aquatic predators showed different sensitivities to AUL ranged between $25 \%$ to $100 \%$.

The means percentages control for NL and AUL showed that, these natural products produced more mortality in mosquito's larvae, and less mortality in their aquatic predators. This finding reflected the advantage of using natural products in comparison to the considerably high cost, more hazardous, resistible and imported insecticides.

\section{Conclusion}

The densities of (An) and (CL) and their aquatic predators seemed to be more in Karkoug breeding sites than Barakat breeding sites.

(SBL) and (T) were not noticed in some breeding sites in Karkoug, while in Barakat breeding sites (T) sometime were not noticed.

Neem leaves and usher latex preparations affected mosquito's larvae more than the aquatic predators in the study areas.

\section{Compliance with ethical standards}

\section{Acknowledgments}

Concerning this original article, great appreciation for the technician Alteraify who gave a big hand in the field work through the villages where the study was conducted and for the faculty of Engineering and Technology, University of Gezira for providing a car for the field work. Thanks, are also extended Mrs. Handi Elamin who types this manuscript.

\section{Disclosure of conflict of interest}

The authors (Abdelmonem E. H. Ali and Mutaman A. A. Kehail) declare no conflicts of interest regarding the publication of this paper.

\section{Statement of ethical approval}

The present research work does not contain any studies performed on animals/humans subjects by any of the authors'.

\section{References}

[1] MDA, Maryland Department of Agriculture. Mosquito Information. Available at: https://mda.maryland.gov/ plants-pests/pages/mosquito_control_program_description.aspx. 2016.

[2] Ralph H. Family Culicidae. Meigen, 1818. Mosquito Taxonomic Inventory. Available at: http://mosquitotaxonomic-inventory. 2008.

[3] Lesley B. The New Shorter Oxford English Dictionary on Historical Principles. Oxford [Eng.]: Clarendon. ISBN 978-0-19-861271-1. 1993.

[4] WHO. World Malaria Report 2017. ISBN 978-92-4-156552-3. 2017.

[5] Claire B. Would it be wrong to eradicate mosquitoes? - BBC News. 2016.

[6] Nils BT, Caminade C, Beierkuhnlein C, Thomas SM. Mosquito-Borne Diseases: Advances in Modeling ClimateChange Impacts. Trends in Parasitology. 2018; 34(3): 227-245.

[7] WHO. Resistance of vector of diseases to pesticides. Tech. Rep., 655, Geneva. 1980.

[8] Ganguli S. Neem: A therapeutic for all seasons. Current Science. 2002; 82(11): 1304.

[9] Chaskara MV, Pramoda SJ, Jeevikaa MU, Chandana PK, Shetteppa G. Letters: MR Imaging Findings of Neem Oil Poisoning. American Journal of Neuroradiology. 2010; 31: 60-61. 
[10] Imran M, Khan H, Shah M, Khan F. Chemical composition and antioxidant activity of certain Morus species. J. Zhejiang Univ. Sci. B. 2010; 11: 973-980.

[11] USDA, United States Department of Agriculture. Calotropis procera (Aiton) Germplasm Resources Information Network. 2010; 10-19.

[12] Morris S, Kupchan JR, Knox JE, Kelsey A, Saenz Renauld JA. Calotropin, a Cytotoxic Principle Isolated from Asclepias curassavica L. Science. 1964.

[13] Kehail MA. Larvicidal potentialities of 20 plant species from Wad Medani. Gezira State on Anopheles arabiensis and Culex quinquefasciatus (Culicidae, Diptera). [Ph.D. Thesis], University of Gezira, Sudan. 1994.

[14] AbdAldafae AA. The effect of neem (Azadirachta indica A. Juss) leaves powder on Anopheles arabiensis Patton (Diptera: Culicidae) larvae, [M.Sc. dissertation], University of Gezira, Sudan. 2009.

[15] Osman ZAM. Potentiality of some natural products preparations against Mosquito (Anopheles and Culex) Larvae and some of their aquatic predators (Field Assessment). 2012.

[16] Rembold H. The azadirachtin-highly active insect growth inhibitors. Recent Advanced Med. Arom. Spice Crops, Today and Tomorrow's, New Delhi. 1991; 1: 31-37.

[17] Chouhan BS, Gupta IL, Rather CS. Calotropis injure to eye. Afro Asian J. Ophthal. 1992; 10(4): $124-125$.

[18] AOAD. Medicinal, Aromatic and poisonus plants in the Arab World, Khartoum. 1988. 